\title{
Attitudes of Montenegrin Consumers Toward Advertising Through Sport Among the Question How Often They Participate in Sports Activities
}

\author{
Jovan Gardasevic, Gorica Zoric and Bojan Masanovic \\ University of Montenegro, Faculty for Sport and Physical Education, Niksic, Montenegro
}

\begin{abstract}
A B S T R A C T
Advertising is an attractive promotional tool for marketers who can use it to strengthen communication with consumers and persuade them to purchasing certain product or service. Hence, there is necessity to analyse their general attitudes among various questions, while this research was aimed at gaining relevant knowledge about the attitudes of Montenegrin consumers toward advertising through sport among the question how often they participate in sports activities. The sample included 342 respondents, divided into six subsample groups: consumers who do not participate in sport activities at all, then consumers who participate in sport activities less than ones a month, next 1-4 a month, 5-10 a month, 11-20 a month, as well as consumers participate in sport activities more than 20 times a month. The sample of variables contained the system of three general attitudes which were modelled by seven-point Likert scale. The results of the measuring were analysed by multivariate analysis (MANOVA) and univariate analysis (ANOVA) and Post Hoc test. Based on the statistical analyses it was found that significant differences occur at multivariate level, as well as between all three variables at a significance level of $p=.01$. Hence, it is interesting to highlight that it was found there are significant differences showed up between the consumers who participate in various sports activities. These results are so important for the marketers, mostly due to the reason they can't merge all the potential consumers who participate in various sports activities into one homogeneous group. This isthe case in previous investigations and this observation presents relevant information.
\end{abstract}

Key words: Attitudes, Advertising, Sports Events, Montenegro

\section{Uvod}

Zaključci pionirskih studija iz navedene oblasti koji su objavljeni od strane Bauer-a i Greiser-a (Popovic, 2011) i Lutz-a (Klačar, i Popović, 2010) pokrenuli su ideje koje se odnose na činjenicu da stavovi potrošača prema reklmairanju predstavljaju jedan od značajnih faktora koji mogu ojačati efikasnost reklamnih kampanja, uglavnom zbog razloga da kognitivna sposobnost potrošača prema reklamiranju jeste sadržana u njihovim osjećanjima i mislima (Muratović, Bjelica, \& Popović, 2014). Ako se nastavi sa istraživanjem ovog pitanja i ode se mnogo dublje, zanimljivo je da se primjećuje postojanje brojnih studija koje su istraživali stavove potrošača prema reklamiranju, ali većina njih smatra stavove potrošača prema reklamiranju samo uopšteno (Bjelica, i Popović, 2011; Popović, 2011b; Popović, Molnar, i Radovanović, 2011a; Popović, Matić, Milašinović, Jakšić, \& Bjelica, 2015a; Popović, Matić, Milašinović, Hadžić, Milošević, i Bjelica, 2015b; Popović, Matić, Milašinović, Vujović, Milošević, i Bjelica, 2015c). U svakom slučaju, neki od njih su zaključili da su stavovi prema reklamiranju pokazali negativan trend tokom 1960-ih i 1970-ih (Popović, Bjelica, Jakšić, \& Georgiev, 2013; Popovic, 2015; Popović, \& Milašinović, 2016), dok su drugi pronašli povoljnije stavove ispitanika u istom periodu (Popovic, 2011). Ove nedosljednosti su navele na sumnju da reklamne kampanje koje koriste elemente iz specifičnih medijuma utiču na stavove potrošača prema reklamiranju u skladu sa tim (Popovic, 2011). Neki autori su vjerovali da je jedan od najrelevantnijih medija, upravo sport, odnosno sportisti i njihovi timovi, sportski događaji i sportski objekti (Bjelica i Popović, 2011; Masanovic,
Zoric, \& Gardasevic, 2017), uglavnom iz razloga što ovi elementi mogu da utiču na stavove potrošača i naprave značajne oscilacije kod stavova u poređenju sa ostalim elementima (Bjelica, Popović, Jakšić, Hadžić, \& Akpinar, 2014b; Bjelica, i Popović, 2015a; Bjelica, \& Popović, 2015b; Bjelica, Gardasevic, Vasiljevic, \& Popovic, 2016a; Bjelica, Gardašević, Vasiljević, \&Popović, 2016c; Zoric, Masanovic, \& Gardasevic, 2017). Iz tog razloga, mnogi istraživači priznaju sport kao nezavisnu reklamnu platformu koju poslovni subjekti mogu koristiti kako bi prevazišli negativne stavove potrošača prema reklamiranju. Samim tim se postavilo i pitanje, kako bavljenje sportskim aktivnostima utiče na stavove potrošača prema reklamiranju u sportu kao jedan od niza problema sa kojim se nije susrećalo mnogo autora do sada (Bjelica, Popovic, \& Akpinar, 2014a; Bjelica, Popovic, \& Akpinar, 2015c; Bjelica, Popovic, \& Akpinar, 2016b; Bjelica, Popovic, \& Akpinar, 2017; Gardasevic, Zoric, \& Masanovic, 2017), a to upravo i jeste cilj ove studije.

\section{Metod}

Populaciju u ovoj studiji su činili studenti sa Univerziteta Crne Gore koji su, u vrijeme anketiranja, imali boravište na teritoriji Crne Gore, dok je uzorak ispitanika organizovan putem kombinovanja ili raslojavanja, tako da su obrađena različita svojstva navedene populacije i različiti prostori na kojima je ona egzistirala.

Upitnici su distribuirani studentima osnovnih studija u štampanom i elektronskom obliku. Ukupno je prikupljeno 349 upitnika, ali je 7 upitnika bilo isključeno iz analize, budući da nisu bili 
adekvatno popunjeni, tako da je u istraživanju učestvovalo, ukupno 342 ispitanika (slučajno odabranih studenta sa Univerziteta Crne Gore). Instrument istraživanja je predstavljao standardizovani upitnik (Popović, 2011) i sastojao se iz dva dijela, generalnih stavova prema reklamiranju u sportu i socio-demografskih karakteristika ispitanika kada je učestalost bavljenja sportskim aktivnostima tokom mjeseca u pitanju. Sistem promjenljivih u ovom upitniku je sadržao tri tvrdnje koje su ispitanici trebali da ocijene prema sedmo-stepenoj Likertovoj skali vrijednosti, kao i šest socio-demografskih karakteristika ispitanika (uopšte se ne bave, manje od jednom mjesečno, 1-4 puta mjesečno, 5-10 puta mjesečno, 11-20 puta mjesečno, i više od 20 puta mjesečno). Popunjavanje upitnika nije trajalo, u prosjeku više od 10 minuta a ispitanici su u anketi učestvovali na dobrovoljnoj osnovi. Važno je naglasiti da je anketa bila anonimna i da su svi odgovori bili strogo poverljivi. Vrijedno je napomenuti i da su ispitanici, i pored svega navedenog imali mogućnost da u svakom momentu opozovu svoje učešće u anketi, ali se niko od njih nije na tako nešto odlučio.

Empirijski podaci su analizirani putem statističkog paketa za društvene nauke (SPSS 20.0), a kao prvi korak, bila je primijenjena deskriptivna statistika kojom su izračunati, prije svega frekvencija, zatim aritmetička sredina, standardna devijacija, kao i mjere asimetrije (Skewness) i spljoštenosti (Kurtosis) za svaku od tvrdnji. Budući da su se promjenljive u ovoj studiji nalazile na naparametrijskim skalama, radi detaljnijih analiza koje su slijedile, bilo je neophodno da se one, primjenom Blomovog postupka, transformišu u skale višeg reda. Zatim su primjenom multivarijatne analize varijanse (MANOVA), univarijatne analize varijanse (ANOVA) i LSD Post Hoc testa utvrđene razlike u generalnim stavovima ispitanika prema reklamiranju u sportu u odnosu na učestalost bavljenja sportskim aktivnostima tokom mjeseca.

\section{Rezultati}

U prvoj tabeli su prikazani deskriptivni statistički podaci za sve tri tvrdnje koje su se odnosile na generalne stavove ispitanika prema reklamiranju u sportu. Prije svega, prikazana je arit-

Tabela 1. Generalni stavovi prema reklamiranju u sportu

\begin{tabular}{lcccccc}
\hline & \multirow{2}{*}{ Mean } & \multirow{2}{*}{ S.D. } & \multicolumn{2}{c}{ Skewness } & \multicolumn{2}{c}{ Kurtosis } \\
\cline { 4 - 7 } & & & Statistic & S.E. & Statistic & S.E. \\
\hline GSS1 & 5.09 & 1.642 & -.549 & .132 & -.546 & .263 \\
GSS2 & 5.51 & 1.506 & -.711 & .132 & -.468 & .263 \\
GSS3 & 5.69 & 1.693 & -.389 & .132 & -.545 & .263 \\
\hline
\end{tabular}

Legenda: Mean - Aritmetička sredina; S.D. - Standardna devijacija; Skewness - Mjera asimetrije; Kurtosis - Mjera spljoštenosti; Statistic - Statistička vrijednost; S.E. - Standardna greška; GSS1 - Moje opšte mišljenje je naklonjeno reklamiranju u sportu; GSS2 - Sveobuhvatno, smatram da je reklamiranje u sportu dobra stvar; GSS3 - Sveobuhvatno, da li ne volite ili volite reklamiranje u sportu

meticka sredina koja oslikava pozitivne vrijednosti stavova kada su sve tri tvrdnje u pitanju, dok vrijednosti standardne devijacije pokazuju da elementi skupa, u prosjeku ne odstupaju znacajno od aritmeticke sredine. Kada se govori o mjerama asimetrije (Skewness) i spljostenosti (Kurtosis), negativne vrijed- nosti asimetrije kod svih promjenljivih pokazuju da je većina rezultata desno od srednje vrijednosti, među većim vrijednostima, dok dok negativne vrijednosti spljostenosti kod svih promjenljivih pokazuje da je raspodjela pljosnatija od normalne tj. da ima vise rezultata nagomilanih na repovima raspodjele.

Tabela 2. Multivarijatna značajnost razlika u sistemu generalnih stavova prema reklamiranju u sportu kod ispitanika sa različitim navikama kada je bavljenje sportskim aktivnostima u pitanju

\begin{tabular}{llccc}
\hline & & N & Mean & S.D. \\
\hline GSS1 & Ne bave se & 4 & 3.50 & .577 \\
& $<1$ & 20 & 4.10 & 1.619 \\
& $1-4$ & 54 & 5.33 & 1.374 \\
& $5-10$ & 26 & 5.31 & 1.850 \\
& $11-20$ & 92 & 4.76 & 1.718 \\
& $>20$ & 146 & 5.34 & 1.578 \\
& Ukupno & 342 & 5.09 & 1.642 \\
\hline GSS2 & Ne bave se & 4 & 3.44 & .577 \\
& $<1$ & 20 & 4.33 & 1.536 \\
& $1-4$ & 54 & 5.12 & 1.514 \\
& $5-10$ & 26 & 5.68 & 1.230 \\
& $11-20$ & 92 & 5.62 & 1.483 \\
& $>20$ & 146 & 5.75 & 1.462 \\
& Ukupno & 342 & 5.43 & 1.506 \\
\hline NSS3 & Ne bave se & 4 & 3.33 & 2.309 \\
& $<1$ & 20 & 3.85 & 1.949 \\
& $1-4$ & 54 & 4.05 & 1.530 \\
& $5-10$ & 26 & 5.30 & 1.789 \\
$11-20$ & 92 & 4.38 & 1.787 \\
& $>20$ & 146 & 4.20 & 1.574 \\
& Ukupno & 342 & 4.07 & 1.693 \\
\hline & & & &
\end{tabular}


Tabela 3. Univarijatna značajnost razlika u sistemu generalnih stavova prema reklamiranju u sportu kod ispitanika sa različitim navikama kada je bavljenje sportskim aktivnostima u pitanju

\begin{tabular}{ccc}
\hline & $\mathbf{F}$ & $\mathbf{p}$ \\
\hline GSS1 & 4.145 & .001 \\
GSS2 & 5.452 & .000 \\
GSS3 & 2.498 & .031 \\
\hline
\end{tabular}

U nastavku ove studije su prikazani komparativni statistički podaci generalnih stavova prema reklamiranju u sportu koji su dobijeni primjenom multivarijatne analize varijanse (MANOVA), univarijatne analize varijanse (ANOVA) i LSD Post Hoc testa, a u cilju utvrđivanja razlike u generalnim stavovima ispitanika prema reklamiranju u sportu u odnosu na učestalost ba- vljenja sportskim aktivnostima.

Inspekcijom druge tabele u kojoj su prikazani rezultati multivarijatne analize, jasno se uočava da u cijelom sistemu upoređivanih parametara postoji statistički značajna razlika u generalnim stavovima prema reklamiranju u sportu u odnosu na učestalost bavljenja sportskim aktivnostima $(\mathrm{p}=.001)$.

Tabela 4. Utvrđivanje značajnih razlika u sistemu generalnih stavova prema reklamiranju u sportu primjenom Post Hoc testa između pojedinačnih entiteta sa različitim navikama kada je bavljenje sportskim aktivnostima u pitanju kod tvrdnje „moje opšte mišljenje je naklonjeno reklamiranju u sportu“

\begin{tabular}{cccccc}
\hline \multicolumn{5}{c}{ „moje opste mišljenje je naklonjeno reklamiranju u sportu“ } \\
\hline Vs & $\begin{array}{c}\text { Ne bave } \\
\text { se }\end{array}$ & $<\mathbf{1}$ & $\mathbf{1}-\mathbf{4}$ & $\mathbf{5}-\mathbf{1 0}$ & $\mathbf{1 1 - \mathbf { 2 0 }}$ \\
\hline$<1$ & .495 & & & & \\
$1-4$ & .028 & .004 & & & \\
$5-10$ & .037 & .012 & .947 & & \\
$11-20$ & .125 & .096 & .038 & .126 & \\
$>20$ & .024 & .001 & .972 & .919 & .007 \\
\hline
\end{tabular}

Inspekcijom treće tabele u kojoj su prikazani rezultati univarijatne analize, jasno se uočava da je, takođe došlo do statistički značajnih razlika u generalnim stavovima prema reklamiranju u sportu u odnosu na učestalost bavljenja sportskim aktivnostima kod sve tri promjenljive.

Inspekcijom naredne tri tabele gdje su prikazani rezultati
Post Hoc testa koji ukazuju na značajnost razlika između parova pojedinacnih entiteta sa razlicitim navikama kada je bavljenje sportskim aktivnostima u pitanju za svaku promjenljivu, budući na rezultate koji su se pojavili na univarijatnom nivou, očekivano se uočava da postoje statisticki značajne razlike pojedinih parametara.

Tabela 5. Utvrđivanje značajnih razlika u sistemu generalnih stavova prema reklamiranju u sportu primjenom Post Hoc testa između pojedinačnih entiteta sa različitim navikama kada je bavljenje sportskim aktivnostima u pitanjukod tvrdnje „sveobuhvatno, smatram da je reklamiranje u sportu dobra stvar“

\begin{tabular}{cccccc}
\hline vs & $\begin{array}{c}\text { Ne bave } \\
\text { se }\end{array}$ & $<\mathbf{1}$ & $\mathbf{1 - 4}$ & $\mathbf{5 - 1 0}$ & $\mathbf{1 1 - 2 0}$ \\
\hline$<1$ & .261 & & & & \\
$1-4$ & .009 & .005 & & & \\
$5-10$ & .002 & .001 & .206 & & \\
$11-20$ & .015 & .011 & .535 & .066 & .024 \\
$>20$ & .002 & .000 & .220 & .616 & .024 \\
\hline
\end{tabular}

Došlo se do zaključka da se kod prve tvrdnje „moje opšte mišljenje je naklonjeno reklamiranju u sportu“ javljaju razlike između ispitanika koji se ne bave sportskim aktivnostima i većine ostalih entiteta; između ispitanika koji se bave sportskim aktivnostima manje od jednom mjesečno i svih entiteta osim is- pitanika koji se bave sportskim aktivnostima 11-20 puta mjesečno; između ispitanika koji se bave sportskim aktinostima 1120 i 1-4 puta mjesečno; između ispitanika koji se bave sportskim aktinostima preko 20 i 11-20 puta mjesečno. Uvijek pozitivnije rezultate vidimo kod grupa koje se više bave sportom.

Tabela 6.Utvrđivanje značajnih razlika u sistemu generalnih stavova prema reklamiranju u sportu primjenom Post Hoc testa između pojedinačnih entiteta sa različitim navikama kada je bavljenje sportskim aktivnostima u pitanju kod tvrdnje „sveobuhvatno, da li ne volite ili volite reklamiranje u sportu“

\begin{tabular}{cccccc}
\hline vs & $\begin{array}{c}\text { Ne bave } \\
\text { se }\end{array}$ & $<\mathbf{1}$ & $\mathbf{1 - 4}$ & $\mathbf{5 - 1 0}$ & $\mathbf{1 1 - 2 0}$ \\
\hline$<1$ & .446 & & & & \\
$1-4$ & .037 & .011 & & & \\
$5-10$ & .027 & .009 & .643 & & \\
$11-20$ & .045 & .014 & .735 & .448 & \\
$>20$ & .040 & .009 & .818 & .490 & .872 \\
\hline
\end{tabular}

Došlo se do zaključka da se kod druge tvrdnje ,,sveobuhvatno, smatram da je reklamiranje u sportu dobra stvar" javljaju razlike između ispitanika koji se ne bave sportskim aktivnosti- ma i svih ostalih entiteta osim ispitanika koji se bave sportom manje od jednom mjesečno; između ispitanika koji se bave sportskim aktivnostima manje od jednom mjesečno i svih osta- 
lih entiteta koji se bave sportskim aktivnostima više puta mjesečno; između ispitanika koji se bave sportskim aktinostima preko 20 i 11-20 puta mjesečno. Možemo uočiti da pripadnici dvije grupe koje se najmanje bave sportom imaju najmanje pozitivne odgovore.

Došlo se do zaključka da se kod treće tvrdnje ,,sveobuhvatno, da li ne volite ili volite reklamiranje u sportu“ pojavljuju razlike prije svega između ispitanika koji se ne bave sportskim aktivnostima i svih ostalih entiteta, osim ispitanika koji se bave sportom manje od jednom mjesečno. Takođe razlike se javljaju između ispitanika koji se bave sportskim aktivnostima manje od jednom mjesečno i entiteta koji se bave sportskim aktivnostima više puta mjesečno. Možemo uočiti da pripadnici tri grupe koje se najmanje bave sportom imaju najmanje pozitivne odgovore.

\section{Diskusija}

S obzirom da su rezultati pokazali da ispitanici imaju veoma pozitivan stav prema reklamiranju u sportu što potvrđuje visoka vrijednost aritmetičke sredine za sve tri promjenljive, kao i da skoro dvije trećine ispitanika imaju pozitivan stav prema reklamiranju u sportu što se ogleda u izrazito negativnim vrijednostima mjera asimetrije, trebalo bi naglasiti da su ovi rezultate usaglašeni sa rezultatima prethodnih istraživanja (Molnar, Lilić, Popović, Akpinar, \& Jakšić, 2011; Popović, Jakšić, Matić, Bjelica, \& Maksimović, 2014; Popović, Bjelica, Georgiev, \& Akpinar, 2011b; Popović, Matić, Milašinović, Jakšić, \& Bjelica, 2015d; Popović, Matić, Milašinović, Hadžić, Milošević, \& Bjelica, 2015e; Popović, Matić, Milašinović, Vujović, Milošević, \& Bjelica, 2015f; Popović, Jakšić, Matić, Bjelica, \& Maksimović, $2015 \mathrm{~g}$ ), i da ne postoje značajne razlike koje bi trebalo pomenuti. Dobijeni rezultati, takođe jasno ukazuju da ispitanici koji žive na različitim lokacijama, kao što su Sjedinjene države,

\section{R E F E R E N C E S}

Bjelica, D. i Popović, S. (2011). Stavovi potrošača prema reklamiranju u sportu u odnosu na učestalost posmatranja sportskih događaja. Sportske nauke i zdravlje, 1(2), 114-119.

Bjelica, D., Popovic, S., \& Akpinar, S. (2014a). Book of Abstracts of the 11th International Scientific Conference on Transformation Process in Sport "Sport Performance". Podgorica: Montenegrin Sports Academy.

Bjelica, D., Popović, S., Jakšić, D., Hadžić, R., \& Akpinar, S. (2014b). How Does Advertising through Sport Work? Evidence from Turkey. In Proceedings book of the 7th International Scientific Conference on Kinesiology "Fundamental and Applied Kinesiology - Steps Forward " (477). Opatija: University of Zegreb, Faculty of Kinesiology.

Bjelica, D., i Popović, S. (2015a). Evolucija reklamiranja sa posebnim osvrtom na reklamiranje u sportu. Sport Mont, 13(43,44,45), 35-41.

Bjelica, D., \& Popović, S. (2015b). Evolution of Advertising with a Specific Retrospection at Sport Advertising. In Book of Abstracts of the 12th International Scientific Conference on Transformation Process in Sport "Sport Performance" (60-61), Podgorica: Montenegrin Sports Academy.

Bjelica, D., Popovic, S., \& Akpinar, S. (2015c). Book of Abstracts of the 12th International Scientific Conference on Transformation Process in Sport "Sport Performance". Podgorica: Montenegrin Sports Academy.

Bjelica, D., Gardasevic, J., Vasiljevic, I., \& Popovic, S. (2016a). Ethical Dilemmas of Sport Advertising. Sport
Turska, Crna Gora i Srbiji, imaju pozitivne stavove prema reklamiranju u sportu, dok je, ipak, poređenja radi, vrijedno navesti da, prema Mittal-u (Popovic, 2011), različite studije ukazuju na negativne stavove kada je reklamiranje proizvoda u tradicionalnim industrijama u pitanju. Prema tome, više je nego evidentno da je primjena sporta u savremenoj poslovnoj komunikaciji uticala da se generalni stavovi potrošača značajno promijene kada je reklamiranje u pitanju, a prepoznavanje privlačnosti sporta je omogućilo poslovnim organizacijama da se približe sportskim potrošačima i na mnogo bezbolniji način utiču na njihovo ponašanje.

Utvrđivanjem razlike u generalnim stavovima ispitanika prema reklamiranju u sportu u odnosu na učestvovanje u sportskim aktivnostima, u ovoj studiji su pronađene razlike u stavovima između ispitanika koji imaju različite navike kada je u pitanju učestvovanje u sportskim aktivnostima. Ove razlike su se pojavile kod svih promjenljivih na univarijatnom nivou. Kod sve tri promjenljive ispitanici koji se ne bave sportskim aktivnostima i koji se bave manje od jednog puta mjesečno imaju negativnije stavove od ostalih ispitanika.

$\mathrm{Na}$ osnovu statističkih analiza, utvrđeno je da se značajne razlike javljaju na multivarijatnom nivou, kao i između nekih varijabli na univerijatnom nivou značajnosti od $p=.01$. Pronađene značajne razlike između ispitanika sa različitom učestalošću u bavljenju sportskim aktivnostima, slažu se sa prethodnim studijama (Bjelica i sar., 2014b; Bjelica, i Popović, 2015a; Bjelica, \& Popović, 2015b; Bjelica i sar., 2016a; Bjelica i sar., 2016c; Gardasevic, Zoric, \& Masanovic, 2017). Ovi rezultati su veoma važni za poslovne subjekte u Crnoj Gori i za naučnu javnost, uglavnom iz razloga što ne mogu spojiti sve potencijalne potrošače koji učestvuju u raznim sportskim aktivnostima u jednu homogenu grupu, o čemu govore i prethodna istraživanja (Bjelica i sar., 2016a; Bjelica i sar., 2016c).

Mont, 14(3), 41-43.

Bjelica, D., Popovic, S., \& Akpinar, S. (2016b). Book of Abstracts of the 13th International Scientific Conference on Transformation Process in Sport "Sport Performance". Podgorica: Montenegrin Sports Academy.

Bjelica, D., Gardašević, J., Vasiljević, I., \&Popović, S. (2016c). Ethical dilemmas of sport advertising. In Book of Abstracts of the 13th International Scientific Conference on Transformation Process in Sport "Sport Performance" (41), Podgorica: Montenegrin Sports Academy.

Bjelica, D., Popovic, S., \& Akpinar, S. (2017). Book of Abstracts of the 14th International Scientific Conference on Transformation Process in Sport "Sport Performance". Podgorica: Montenegrin Sports Academy.

Gardasevic, J., Zoric, G., \& Masanovic, B. (2017). Attitudes of Turkish consumers toward advertising through sport among the question how often they participate in sports activities. Journal of Anthropology of Sport and Physical Education, 1(1), 23-27. doi: 10.26773/jaspe.171004

Klačar, M. \& Popović, S. (2010). Reklamiranje u sportu kao efektivno sredstvo savremene komunikacije. Teme, 4, 12191230.

Masanovic, B., Zoric, G., \& Gardasevic, J. (2017). Attitudes of Turkish consumers toward advertising through sport among the frequency of watching sports events. Journal of Anthropology of Sport and Physical Education, 1(1), 3-7. doi: 10.26773 /jaspe. 171001 
Molnar, S., Lilić, Lj., Popović, S., Akpinar, S., \& Jakšić, D. (2011). Attitudes of various demographic groups toward advertising through sport at METU. Facta Universitatis, Series: Physical Education and Sport, 9(3), 255-263.

Muratović, A., Bjelica, D., \& Popović, S. (2014). Examining beliefs and attitudes toward advertising through sport among montenegrin consumers. Facta Universitatis, Series: Physical Education and Sport, 12(2), 95-104.

Popovic, S. (2011). Reklamiranje u sportu kao efektivno sredstvo savremene poslovne komunikacije. Neobjavljena doktoska disertacija, Novi Sad: Univerzitet u Novom Sadu.

Popović, S. (2011b). Stavovi potrošača prema reklamiranju u sportu u odnosu na učestalost kupovine sportskih proizvoda. Sport Mont, 9(28,29,30), 140-147.

Popović, S., Molnar, S. \&Radovanović, D. (2011a). Stavovi potrošača prema reklamiranju u sportu u odnosu na učestalost bavljenja sportskim aktivnostima. Sport Mont, 9(28,29,30), 148-155.

Popović, S., Bjelica, D., Georgiev, G., \& Akpinar, S. (2011b). Comparison of attitudes toward advertising through sport between Montenegrin and Turkish stakeholders. In Proceedings book of the 6th International Scientific Conference on Kinesiology "Integrative Power of Kinesiology" (612). Opatija: University of Zegreb, Faculty of Kinesiology.

Popović, S., Jakšić, D., Matić, R., Bjelica, D., \& Maksimović, N. (2014). Examining Beliefs and Attitudes toward Advertising through Sport among Serbian Consumers. In Book of abstracts of International conference "Economics and Management of Sports 2014" (pp. 11-12). Brno: Faculty of Sports Studies.

Popović, S., Bjelica, D., Jakšić, D, \& Georgiev, G. (2013). How does Advertising Through Sport Work? Evidence from Montenegro. In Book of Abstracts of the $18^{\text {th }}$ Annual Congress of the European College of Sport Science (444-445), Barcelona: National Institute of Physical Education of Catalonia.

Popović, S., Matić, R., Milašinović, R., Jakšić, D., \&Bjelica, D. (2015a). Stavovi srbijanskih potrošača prema reklamiranju u sportu u odnosu na učestalost bavljenja sportskim aktivnostima. Sport Mont, 13(43,44,45), 50-56.

Popović, S., Matić, R., Milašinović,R., Hadžić, R., Milošević, Z., \& Bjelica, D. (2015b). Stavovi srbijanskih potrošača prema reklamiranju u sportu u odnosu na učestalost kupovine sportskih proizvoda. Sport Mont, 13(43,44,45), 262-269.

Popović, S., Matić, R., Milašinović, R., Vujović, D., Milošević, Z. \&Bjelica, D. (2015c). Stavovi srbijanskih potrošača prema reklamiranju u sportu u odnosu na učestalost posmatranja sportskih događaja. Sport Mont, 13(43,44,45), 270-276.

Popović, S., Matić, R., Milašinović, R., Jakšić, D., \&Bjelica, D. (2015d). Attitudes of Serbian Consumers toward Advertising through Sport among the Question How Often They Participate in Sports Activities. In Book of Abstracts of the 12th International Scientific Conference on Transformation Process in Sport "Sport Performance" (58-59), Podgorica: Montenegrin Sports Academy.

Popović, S., Matić, R., Milašinović, R., Hadžić, R., Milošević, Z., \& Bjelica, D. (2015e). Attitudes of Serbian Consumers toward Advertising through Sport among the Question How Often Consumers Purchase Sporting Goods. In Book of Abstracts of the 12th International Scientific Conference on Transformation Process in Sport "Sport Performance" (5960), Podgorica: Montenegrin Sports Academy.

Popović, S., Matić, R., Milašinović, R., Vujović, D., Milošević, Z., \& Bjelica, D. (2015f). Attitudes of Serbian Consumers toward Advertising through Sport among the Frequency of Watching Sports Events. In Book of Abstracts of the 12th International Scientific Conference on Transformation Process in Sport "Sport Performance" (60), Podgorica: Montenegrin Sports Academy.

Popović, S., Jakšić, D., Matić, R., Bjelica, D., \& Maksimović, N. (2015g). Examining Beliefs and Attitudes toward Advertising through Sport among Serbian Consumers. Studia Sportiva, 9(1), 225-231.

Popovic, S. (2015). Sport Nowadays (In Montenegrin). In D. Bjelica (Ed.), Advertising Role of Sponsorship in Modern Sport (pp. 111-116). Podgorica: Montenegrin Sports Academy.

Popović, S. \& Milašinović, R. (2016). Model of Advertising Communication in Sport. Sport Mont, 14(1), 33-38.

Zoric, G., Masanovic, B., \& Gardasevic, J. (2017). Attitudes of Turskish consumers toward advertising through sport among the question how often consumers purchase sporting goods. Journal of Anthropology of Sport and Physical Education, 1(1), 17-21. doi: 10.26773/jaspe.171003

J. Gardasevic

University of Montenegro, Faculty for Sport and Physical Education, Narodne omladine bb, Niksic, Montenegro

e-mail:jovan@ac.me 
